\title{
O Impacto Econômico do Financiamento da Ciência no Brasil: um estudo comparativo entre importação e produção de um bem de capital em nanotecnologia
}

\author{
Área 6.2: Políticas de Ciência, Tecnologia e Inovação
}

\author{
Celso Bissoli Sessa ${ }^{1}$ \\ Ado Jorio de Vasconcelos ${ }^{2}$ \\ Márcia Dias Diniz Costa ${ }^{3}$ \\ Márcia Siqueira Rapini ${ }^{4}$
}

\begin{abstract}
RESUMO: Esse artigo apresenta uma análise sobre o impacto gerado na economia brasileira pela nacionalização e comercialização de um determinado bem de capital para uso em pesquisas científicas em nanociência e nanotecnologia. Tal impacto é calculado utilizando a Matriz de Insumo-Produto Brasileira, considerando três cenários: (i) compra do equipamento importado; (ii) compra do equipamento nacional, considerando montagem no Brasil a partir de componentes importados e nacionais; e (iii) compra do equipamento nacional, considerando a situação, fictícia no presente, em que todos os componentes do equipamento são produzidos no Brasil. Demonstra-se que o impacto econômico da compra de equipamentos nacionais torna o investimento em ciência superavitário, independentemente dos resultados científicos, tecnológicos ou de inovação advindos das pesquisas a serem realizadas, e propõe-se a nacionalização de bens de capital e insumos para pesquisa como modelo sustentável para viabilizar economicamente o desenvolvimento científico e tecnológico nacional.
\end{abstract}

PALAVRAS-CHAVE: Instrumentação Científica; Matriz de Insumo-Produto, Impacto Econômico.

CÓDIGOS JEL: C67, D57, O30.

\section{The Economic Impact of the Financing of Science in Brazil: a comparative study between import and production of a nanotechnology equipment}

\begin{abstract}
This article presents an analysis about the economic impact in the Brazilian economy by the nationalization and commercialization of a capital asset used in scientific research in nanoscience and nanotechnology. This impact is calculated using the Brazilian Input-Output Matrix, considering three scenarios: (i) purchase of imported equipment; (ii) purchase of national equipment, considering assembly in Brazil from imported and domestic components; and (iii) purchase of national equipment, considering the situation, fictitious at present, in which all components of the equipment are produced in Brazil. It is demonstrated that the economic impact of the purchase of national equipment makes a surplus to investment in science, regardless of the scientific, technological or innovation results coming from the researches to be carried out, and it proposes the nationalization of capital goods and research inputs as sustainable model to economically make possible the national scientific and technological development.
\end{abstract}

KEYWORDS: Scientific Instrumentation; Matrix Input-Output, Economic Impact.

JEL-CODES: C67, D57, O30.

\footnotetext{
${ }^{1}$ Professor do Departamento de Economia da Universidade Federal do Espírito Santo (UFES).

${ }^{2}$ Professor do Departamento de Física da Universidade Federal de Minas Gerais (UFMG).

${ }^{3}$ Programa de Pós-Graduação em Inovação Tecnológica e Biofarmacêutica da UFMG.

${ }^{4}$ Professora do Centro de Desenvolvimento e Planejamento Regional (CEDEPLAR) da UFMG. 


\section{Introdução}

As pesquisas científicas, dado o aumento da complexidade dos estudos em determinadas áreas, requerem cada vez mais investimentos em infraestrutura tecnológica para aumentar a capacidade de se observar e medir fenômenos naturais. Especificamente em relação às ciências experimentais, o acesso a equipamentos de alta tecnologia é fundamental para o avanço do conhecimento, embora a pesquisa para o desenvolvimento de tais equipamentos seja pouco considerada pelo meio científico brasileiro.

A ênfase dada ao papel da instrumentação científica no progresso do conhecimento variou ao longo dos últimos 80 anos (SHINN, 2001). Neste período, os instrumentos científicos foram classificados desde meros aparatos para comprovação de teorias até elementos fundamentais para o nascimento de novas disciplinas. Ao tratar deste assunto, Shinn (2001) destaca que foi primeiramente no campo da astronomia que houve a percepção da instrumentação como dando estrutura a um campo científico. De fato, só com o desenvolvimento dos primeiros radiotelescópios foi possível desvendar eventos e descobrir corpos celestes.

Além de dar estrutura a um campo científico, a instrumentação pode ampliar o rol de aplicações interdisciplinares de um efeito mensurável e, quando altamente difundida, pode modificar a estrutura de organização do trabalho nas instituições. De um ponto de vista mais estratégico, a instrumentação pode garantir o monopólio do conhecimento ao grupo que detém o acesso à tecnologia e, com isso, proporcionar vantagens a profissionais e a instituições.

Porém, ao se considerar os custos e os riscos envolvidos nas atividades de pesquisa necessárias para o desenvolvimento de instrumentos científicos, o papel desempenhado pelo Estado passa a ser fundamental para criar as condições adequadas de estímulo à realização das atividades de pesquisa científica. A literatura acadêmica e as evidências empíricas reforçam a ideia de que elevados níveis de investimento em ciência e tecnologia são essenciais para garantir o crescimento econômico no longo prazo.

Sob a perspectiva socioeconômica, o domínio do conhecimento de tecnologias de instrumentação é condição básica para a competitividade científica e industrial do país. As necessidades de investimento e de indução da pesquisa em ciência no Brasil, apesar dos avanços, ainda contrastam com os modelos de industrialização historicamente adotados pelo país, que basicamente foram estruturados sobre a importação maciça de tecnologia e que, em geral, inibiram o desenvolvimento de soluções tecnológicas nacionais.

Neste trabalho, além de se apontar a relevância do tema, procura-se demonstrar, por meio de um estudo de caso, que a estratégia de investimento governamental em estruturas para gerar instrumentação de alta tecnologia pode gerar efeitos positivos sobre a economia brasileira, em oposição aos efeitos diretos da importação de tecnologia. A mensuração do impacto econômico do investimento em instrumentação será feita a partir da Matriz de Insumo-Produto do Brasil, que reflete as relações de interdependência entre os setores. Uma das principais contribuições deste trabalho reside na identificação das distribuições, intensidades e transmissões dos efeitos projetados no sistema produtivo.

Para melhor entendimento, o artigo será dividido em quatro seções, além desta introdução e das considerações finais. A seção 2 aborda a discussão sobre os argumentos econômicos em favor do financiamento público à ciência e um breve histórico do desenvolvimento da Ciência e da Tecnologia no Brasil, com a finalidade de contextualizar o cenário no qual esse investimento em instrumentação irá ocorrer. Na seção 3 é apresentado um panorama da nanotecnologia no Brasil, sendo apresentado o projeto do LabNS (Laboratório de Nanoespectroscopia), estudo de caso deste trabalho. Na seção 4 é apresentado o modelo de insumo-produto, base metodológica deste artigo para o estudo de impacto econômico. E, finalmente, a seção 5 será composta pelo estudo de impacto econômico realizado através da matriz de insumo-produto. Esta seção conterá, ainda, uma breve descrição dos resultados obtidos, seguido pela última seção: as considerações finais.

\section{Financiamento Público e o Desenvolvimento da Ciência e da Tecnologia no Brasil}

A seção 2 aborda a discussão sobre os argumentos econômicos em favor do financiamento público à ciência e um breve histórico do desenvolvimento da Ciência e da Tecnologia no Brasil, com a finalidade de contextualizar o cenário no qual esse investimento em instrumentação irá ocorrer. 


\subsection{Financiamento Público à Ciência}

A relação da ciência com a tecnologia apresenta grande complexidade, de maneira que as ideias comumente aceitas sobre essa relação (a da ciência sendo produzida e, posteriormente, se transformando em tecnologia), definitivamente não se resume à única possibilidade. Rosenberg (2006) pondera que, em muitos casos, a tecnologia molda os empreendimentos científicos, ao fornecer problemas de ordem prática a serem explicados pela pesquisa básica. Ao analisar inúmeros exemplos ao longo da história, Rosenberg (1982) observou que muitas tecnologias foram desenvolvidas a partir de tentativas e erros e que, à época, não havia nenhum conhecimento científico que as explicassem. Apenas após o desenvolvimento dessas tecnologias é que se procurava criar teorias para explicá-las. Para ele, a tecnologia é um "enorme repositório de conhecimento empírico para ser investigado e avaliado pelos cientistas" (ROSEMBERG, 1982, p. 144). Isso significa que a ciência é, até certo ponto, endógena e, muitas vezes, ad hoc. Portanto, a ciência deve ser considerada como líder e, ao mesmo tempo, seguidora dos avanços tecnológicos.

$\mathrm{O}$ argumento econômico a favor do financiamento público à ciência só foi elaborado em profundidade após a Segunda Guerra Mundial com o manifesto de Vannevar Bush de 1946. Contudo, conforme indicado por Freeman e Soete (2005), o argumento já havia sido apresentado em um passado distante. A primeira defesa clara de uma política nacional de Ciência e Tecnologia (C\&T) de apoio público à pesquisa foi realizada por Francis Bacon (1627), que defendia a criação de um grande instituto de pesquisa - "A casa de Salomão" - que utilizaria os resultados de expedições e exploração científica de todo o mundo para estabelecer o "conhecimento das causas e dos movimentos secretos das coisas" (pg.639). No Reino Unido, Bernal (1939), físico e socialista, argumentava a favor de um programa de governo no qual alocações de recursos para a ciência seriam orientadas para as necessidades sociais e os programas deveriam ser monitorados pelo governo.

A Segunda Guerra Mundial e o período posterior evidenciaram a importância da ciência pública no progresso tecnológico. No final de 1944, o presidente Roosevelt pediu a Vannevar Bush, diretor do Office for Scientific Research and Development (OSRD), criado durante a guerra, que argumentasse a favor da extensão do apoio do governo à ciência básica mesmo nos tempos de paz. Antes que Vannevar apresentasse seu relatório, Roosevelt estava morto, mas o relatório "Science, the Endless Frontier" estabelecia a visão de como os EUA poderiam manter seu investimento em pesquisa básica quando a guerra terminasse, ao mesmo tempo que sinalizava para a redução do controle do governo sobre a realização das pesquisas. Mais tarde, a visão da ciência básica e de sua relação com inovação tecnológica, apresentada por Bush, tornouse alicerce da política científica nacional, sendo também a inspiração para a implementação da política científica em vários países.

O argumento econômico para o financiamento público à ciência foi elaborado posteriormente por Nelson (1959) e Arrow (1962). Para Arrow (1962), os processos de invenção e de pesquisa são caracterizados pela produção de informação e envolvem risco, no sentido de que os resultados não podem ser previstos perfeitamente a partir dos insumos. Em vista disto, para o autor, se uma empresa considera um projeto que possui risco que ela mesma é incapaz de reduzir, então ela teria menor propensão a arcar com este investimento, comparativamente a um investimento seguro, principalmente por ter dificuldade em apropriar-se de todo o retorno de seus esforços de P\&D. Desta forma, há um problema claro de subalocação de recursos para atividades desta natureza. Para as atividades de pesquisa básica, este subinvestimento seria ainda maior. Como as incertezas envolvidas desencorajam os investidores privados, Arrow conclui que, para uma alocação ótima de recursos para a invenção e a pesquisa, seria necessário que o governo ou uma instituição não governamental financiasse este tipo de atividade.

Para Nelson (1959), o subinvestimento privado em pesquisa básica é causado por características da atividade de pesquisa básica: incerteza, presença do acaso e a existência de grandes externalidades. A pesquisa básica é caracterizada pela incerteza quanto aos resultados esperados. Esta incerteza aumenta com a distância entre as questões levantadas pela pesquisa científica e sua aplicação prática. A pesquisa pode levar para resultados e aplicações longe do esperado, indicando a presença do acaso. As descobertas da pesquisa básica podem ter muitas aplicações, em diferentes áreas, caracterizando-se, assim, pela presença de externalidades. Há, portanto, um trade-off intrínseco e dinâmico associado a medidas políticas que objetivam aumentar os incentivos para pesquisa básica realizada privadamente porque podem envolver, ao mesmo tempo, limitações de segredo ou de patente para a difusão do conhecimento. Em vista disto, para 
Nelson, as universidades possuem vantagem comparativa na realização de pesquisa básica. A universidade é um local melhor do que empresa privada para desempenhar a pesquisa básica financiada publicamente.

Além da realização de pesquisa básica, nos países em desenvolvimento as universidades funcionam como uma "antena" para identificar os avanços científicos e tecnológicos da fronteira internacional. Assim, alguns investimentos públicos em pesquisas nas universidades serviriam, principalmente, para garantir acesso a redes de fluxos de informações tecnológicas relevantes que funcionam como um instrumento de focalização para identificar oportunidades tecnológicas e como forma de ampliar a capacidade de absorção de um sistema de inovação (CASSIOLATO e ALBUQUERQUE, 1998).

\subsection{Substituição de Importação e Desenvolvimento da Ciência e da Tecnologia no Brasil}

Na América Latina, as ideias de Raul Prebisch e de Celso Furtado deram origem às teorias que justificaram a criação, durante os anos 1950 e 1960, de programas voltados para a substituição de importações. Essas teorias atribuíam o baixo grau de desenvolvimento alcançado pelos países latinoamericanos às suas estruturas econômicas, que estavam fortemente baseadas na exportação de produtos primários de baixo valor agregado ao mesmo tempo em que eram muito dependentes de produtos industrializados importados (SESSA, 2009).

As ideias que surgiram a partir de então se baseavam na constatação de que para tornar o processo de absorção de tecnologias pelos países menos desenvolvidos mais eficiente, seria necessária uma infraestrutura científica e tecnológica mais adequada (WOLFFENBÜTTEL, 2001). Isso significava que seria necessário que se consolidasse uma estrutura científica e tecnológica que estivesse constantemente articulada com o governo e com o setor produtivo, indicando que a inserção da ciência e da tecnologia, de forma mais incisiva na economia, era condição sine qua non para o processo de desenvolvimento.

Apenas após o término da Segunda Guerra Mundial é que as atividades industriais no Brasil foram intensificadas. Assim como ocorreu em muitos países da América Latina, houve grande esforço para se promover o processo de substituição de importações para atender ao mercado interno, que já existia e estava em crescimento. A política industrial que foi implantada no Brasil a partir dos anos 1950 procurou promover a substituição de importações através de uma excessiva proteção do mercado interno. A estratégia adotada foi importar a tecnologia utilizada para a produção de bens de consumo e bens intermediários (VOGT e CIACCO, 1998). O que houve, porém, foi a importação maciça de tecnologia e um transplante intenso de fábricas prontas com tecnologias já muito bem dominadas (RAPPEL, 1999).

Neste mesmo período, a política científica e tecnológica começou a ganhar forma com a criação do Conselho Nacional de Desenvolvimento Científico e Tecnológico (CNPq) e a Comissão de Aperfeiçoamento de Pessoal de Nível Superior (Capes), ambos voltados para a formação de pessoal qualificado para atender as demandas do setor produtivo. Posteriormente, criou-se, em 1967, a Financiadora de Estudos e Projetos (Finep), que procurava apoiar estudos e projetos de interesse para o desenvolvimento econômico, social, científico e tecnológico do país, seguindo as metas e prioridades setoriais estabelecidas pelo governo federal.

O que se observou, portanto, foi a montagem, durante os anos 1950 e 1960, da base institucional brasileira necessária ao desenvolvimento científico e tecnológico. Porém, os acontecimentos da época, como a implantação da indústria automobilística, a construção de estradas e hidrelétricas e a expansão das fronteiras agrícolas no cerrado, ao invés de servirem como oportunidade para geração de tecnologias próprias, só causaram aumento da dívida externa e da dependência tecnológica (MAIA, 2005).

Embora tenha havido a criação dessa base institucional, o desenvolvimento da ciência e da tecnologia no Brasil só se tornou um objetivo claro e específico na política do governo federal quando foi criado, em 1968, o Programa Estratégico de Desenvolvimento (PED). Esse programa propôs a criação do Sistema Nacional de Desenvolvimento em Ciência e Tecnologia (SNDCT), de Planos Básicos de Ciência e Tecnologia, que seriam responsáveis pela execução dos planos nacionais de desenvolvimento, e do Fundo Nacional de Desenvolvimento de Ciência e Tecnologia (FNDCT), que financiaria o SNDCT (RAPINI, 2004).

Durante a década de 1970, parte significativa do desenvolvimento científico e tecnológico no Brasil ficou restrito às universidades, aos institutos de pesquisa e às empresas estatais. E as empresas continuavam importando tecnologias de outros países. A partir de 1971, a Finep passou a administrar os recursos do 
FNDCT. Desde então, até o início dos anos 1990, a Finep foi a principal responsável pela implantação de infraestrutura de ciência e de tecnologia no Brasil (CASSIOLATO e ALBUQUERQUE, 1998).

Até o início dos anos 1980, estabeleceu-se no Brasil um parque industrial diversificado que demandava, de forma geral, apenas prestação de serviços de caráter rotineiro, principalmente em relação a análises e ensaios de produtos. Esse baixo requerimento de ciência e de tecnologia gerava, consequentemente, pequena participação do setor industrial no sistema de inovação. Além disso, em função dos efeitos da crise econômica de 1979, os investimentos públicos em ciência e tecnologia durante esta década foram reduzidos e houve transferência de recursos públicos de atividades de pesquisa e desenvolvimento das universidades para centros do governo e empresas estatais. $\mathrm{O}$ resultado foi, inevitavelmente, o sucateamento dos laboratórios das universidades (VOGT e CIACCO, 1998).

Em 1985 foi criado o Ministério da Ciência e Tecnologia ${ }^{5}$, cujas ações procuraram expandir a infraestrutura de ciência e tecnologia através, principalmente, do estímulo ao desenvolvimento de recursos humanos. Como exemplo, cita-se a criação, em 1987, do Programa de Formação de Recursos Humanos para Áreas Estratégicas (RHAE), que procurava atender demandas específicas das instituições através de projetos de pesquisa e desenvolvimento nas áreas de biotecnologia, informática e microeletrônica, novos materiais, mecânica de precisão e química fina (ASSAD, 1998).

O setor privado, durante os anos 1980, pouco se envolveu nas atividades de pesquisa e desenvolvimento, refletindo, por um lado, a situação das empresas nacionais e, por outro, as características das políticas industriais implementadas. A estrutura industrial montada no país não colocou o setor de ponta, em termos tecnológicos, sob o comando das empresas brasileiras. $\mathrm{Na}$ verdade, foram as multinacionais que se constituíram nas empresas mais complexas em termos tecnológicos. Essa situação foi resultado das políticas industriais implementadas, que beneficiavam as empresas através de proteções e subsídios dados pelo setor público sem, no entanto, exigir contrapartidas em termos de capacitação tecnológica. Dessa forma, a infraestrutura de ciência e tecnologia que foi montada no Brasil se limitou, em grande medida, ao setor público (CASSIOLATO e ALBUQUERQUE, 1998).

Assim como em muitos países latino-americanos, o Brasil, na década de 1990, intensificou seu processo de abertura com os governos Collor e Itamar (1992 a 1994). Esperava-se que as empresas fossem estimuladas a modificarem suas estratégias para adquirir maior competitividade. Com o processo de abertura, especialmente por meio da revogação da Lei do Similar Nacional e de várias restrições à importação, as atenções se voltaram para a busca de qualidade, produtividade e competitividade por parte das empresas. Os resultados esperados, porém, não foram alcançados, pois a especialização da indústria brasileira em bens e serviços de baixo conteúdo tecnológico não possibilitou a inserção rápida do país naquele alto nível de tecnologia incorporado nas empresas estrangeiras. Esses setores não estavam suficientemente preparados, seja em termos de aprendizado, seja em termos de interação, para tal inserção (FERRARI, 2006).

Em função da reduzida capacidade interna de desenvolvimento de atividades de pesquisa e desenvolvimento, no Brasil a estrutura industrial ainda permanece bastante dependente de desenvolvimentos tecnológicos exteriores. Conforme pode ser observado no Gráfico 1, de 1992, ano em que se iniciou o processo de abertura da economia nacional à concorrência externa, a 2004, houve crescimento significativo das remessas ao exterior em função de contratos de transferência de tecnologia. Esse crescimento indica que, apesar dos esforços internos para desenvolvimento tecnológico próprio, ainda se importa e se licencia muita tecnologia dos países mais avançados. No caso brasileiro, a situação se agrava mais em virtude da forte presença de empresas transnacionais, que desenvolvem grande parte de suas tecnologias em seus países de origem.

\footnotetext{
${ }^{5}$ No início de 1989, o governo Sarney extinguiu o MCT, transferindo suas funções ao Ministério do Desenvolvimento Industrial, Ciência e Tecnologia. Por pressão da comunidade científica, o governo criou a Secretaria Especial de Ciência e Tecnologia, sendo transformada, em dezembro daquele ano, em Ministério. Porém, o Ministério foi novamente extinto meses depois com a reforma administrativa implementada pelo governo Collor. Somente ao final do ano de 1992, durante o governo Itamar, é o que o Ministério de Ciência e Tecnologia foi novamente recriado (FRANÇA, 2001).
} 
Gráfico 1 - Remessas ao Exterior por Transferência de Tecnologia (em bilhões de dólares) - 1992 a 2004

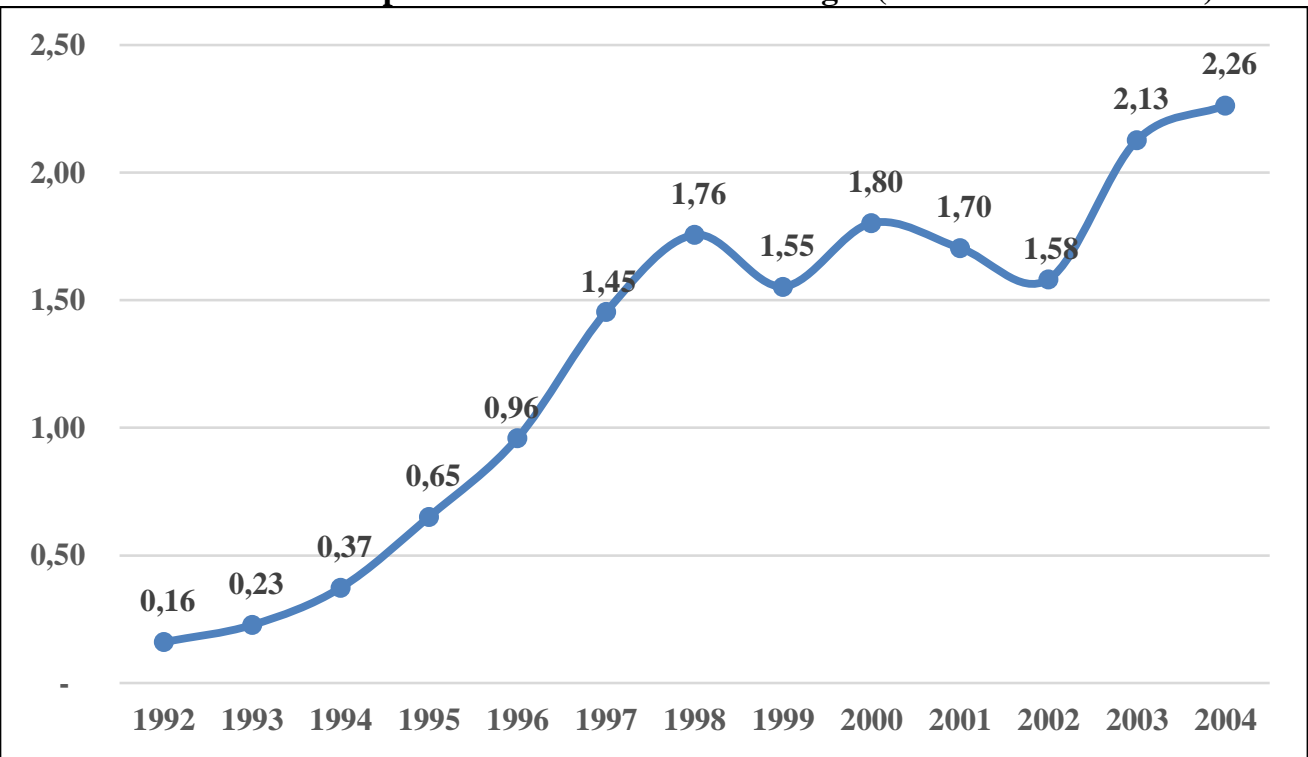

Fonte: MCTI - Indicadores de Ciência e Tecnologia

Ao longo dos anos 2000, foram propostas Políticas Industriais que procuraram ampliar a competitividade e eficiência das empresas brasileiras, bem como fomentar o processo de inovação nas empresas. A estrutura de investimentos nacionais em ciência e tecnologia tem apresentado evolução significativa ao longo dos últimos anos, conforme pode ser observado na Tabela 1.

Tabela 1 - Dispêndio Nacional em Ciência e Tecnologia, em bilhões de R\$ (2000 - 2014)

\begin{tabular}{|c|c|c|c|c|c|c|c|}
\hline \multirow{3}{*}{ Ano } & \multicolumn{7}{|c|}{ Ciência e Tecnologia $(\mathrm{C \& T})$} \\
\hline & \multicolumn{3}{|c|}{ Pesquisa e Desenvolvimento (P\&D) } & \multicolumn{3}{|c|}{$\begin{array}{c}\text { Atividades Científicas e } \\
\text { Técnicas Correlatas (ACTC) }\end{array}$} & \multirow[t]{2}{*}{ Total } \\
\hline & Total & Público (\%) & Privado $(\%)$ & Total & Público (\%) & Privado (\%) & \\
\hline 2000 & 12,56 & 51,70 & 48,30 & 3,27 & 65,76 & 34,24 & 15,83 \\
\hline 2001 & 13,97 & 53,30 & 46,70 & 3,68 & 57,17 & 42,83 & 17,65 \\
\hline 2002 & 15,03 & 51,63 & 48,37 & 4,72 & 47,29 & 52,71 & 19,75 \\
\hline 2003 & 17,16 & 51,41 & 48,59 & 5,10 & 44,47 & 55,53 & 22,27 \\
\hline 2004 & 18,86 & 49,49 & 50,51 & 6,57 & 49,47 & 50,53 & 25,43 \\
\hline 2005 & 21,75 & 47,66 & 52,34 & 6,42 & 50,25 & 49,75 & 28,18 \\
\hline 2006 & 23,80 & 50,03 & 49,97 & 6,73 & 57,14 & 42,86 & 30,54 \\
\hline 2007 & 29,41 & 51,62 & 48,38 & 8,05 & 56,96 & 43,04 & 37,46 \\
\hline 2008 & 35,11 & 50,36 & 49,64 & 10,31 & 52,69 & 47,31 & 45,42 \\
\hline 2009 & 37,28 & 52,29 & 47,71 & 14,11 & 52,45 & 47,55 & 51,39 \\
\hline 2010 & 45,07 & 51,12 & 48,88 & 17,15 & 56,79 & 43,21 & 62,22 \\
\hline 2011 & 49,87 & 52,90 & 47,10 & 18,32 & 48,90 & 51,10 & 68,19 \\
\hline 2012 & 54,25 & 54,93 & 45,07 & 22,21 & 46,11 & 53,89 & 76,46 \\
\hline 2013 & 63,74 & 57,70 & 42,30 & 21,90 & 50,77 & 49,23 & 85,65 \\
\hline 2014 & 73,25 & 52,67 & 47,33 & 22,68 & 50,11 & 49,89 & 95,94 \\
\hline
\end{tabular}

Fonte: MCTI - Indicadores de Ciência e Tecnologia. Elaboração própria.

Os gastos em pesquisa e desenvolvimento, que correspondem à maior parte do gasto total em ciência e tecnologia no país, passaram de 12,56 bilhões de reais em 2000 para 73,25 bilhões em 2014, sendo que a participação dos gastos públicos flutuou em torno da metade do total gasto. Um aumento importante nos valores também é observado nas atividades científicas e técnicas correlatas, que apesar de representarem menor parcela dos gastos totais, passaram de 3,27 bilhões de reais em 2000 para 22,68 bilhões em 2014. Nestas atividades, a participação do gasto público inicialmente era bastante superior ao gasto privado, porém, ao longo dos anos, as diferenças entre as duas esferas se reduz gradativamente, de modo a encerrarem a série histórica com igual participação nos gastos.

Apesar das participações dos gastos públicos e privados no total investido em ciência e tecnologia serem similares, o perfil destes gastos apresenta diferenças significativas, em consonância com as discussões sobre o financiamento público à ciência. Dos gastos públicos entre 2000 e 2014, em média $35,96 \%$ do total foram investidos na pós-graduação nas instituições de ensino superior. Isso evidencia o importante papel desempenhado pelo poder público no financiamento das atividades de pesquisa básica, 
uma vez que tais atividades buscam novos conhecimentos e diferentes compreensões científicas, gerando novas hipóteses, teorias e leis, e que não estão direcionadas, a princípio, a nenhuma aplicação prática específica. Do gasto privado, no mesmo período, em média 72,92\% do total foram destinados às atividades de pesquisa e desenvolvimento nas próprias empresas, enquanto apenas 2,95\% foram gastos na pósgraduação. Isso porque as pesquisas aplicadas, voltadas para atingir objetivos específicos e possíveis usos para os descobrimentos da pesquisa básica, ocorrem com mais frequência internamente às firmas.

\section{A Instrumentação Científica e a Nanociência}

\subsection{Panorama Geral}

A preocupação com a instrumentação científica nacional remonta ao início dos anos 80 tendo-se consolidado com a elaboração do SINST - Subprograma de Instrumentação dentro do PACDT. O Subprograma procurava contemplar a produção nacional de instrumentos, bem como o estabelecimento de competências que permitissem o domínio científico e tecnológico do setor. O SINST deixou legados importantes como o embrião de um Sistema de Informação em Instrumentação, e subsídios para a formulação de políticas para o desenvolvimento do setor (Stal e Cerantola, 1989).

A nanociência tem apresentado grande potencial para revolucionar a tecnologia de forma ampla, da medicina à engenharia (ALVES, 2005; FERREIRA e ALBUQUERQUE, 2005). Os bens de capital e de consumo para o avanço da nanociência ainda estão em fase de desenvolvimento no mundo e têm valores muito elevados devido ao alto grau tecnológico agregado, ficando obsoletos com alguns anos de uso devido à velocidade do desenvolvimento da nanotecnologia. Em muitos casos, são segredos de estado, não chegando ao Brasil, ou chegando em suas versões menos avançadas. Porém, apesar disso, o Brasil possui significativa formação de recursos humanos nessa área, formação fundamentada no trabalho realizado com equipamentos e materiais de consumo majoritariamente importados. De acordo com uma pesquisa realizada feita pela Sociedade Brasileira de Física (Tabela 2), a instrumentação científica foi apontada como um dos principais gargalos a serem superados para que a Física brasileira se torne mais competitiva.

Tabela 2 - Gargalos de infraestrutura de acordo com cada comunidade de Física

\begin{tabular}{|c|c|c|c|c|c|c|c|c|}
\hline \multirow[b]{2}{*}{ Comunidades de Física } & \multirow[b]{2}{*}{ Respostas } & \multicolumn{7}{|c|}{ Gargalos } \\
\hline & & 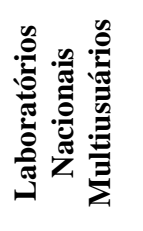 & 焉 & 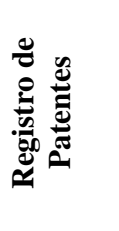 & 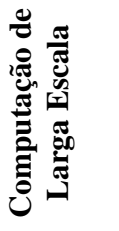 & 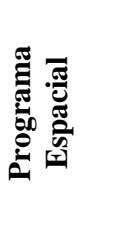 & 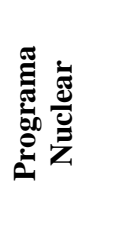 & 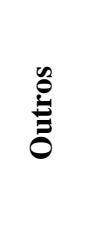 \\
\hline $\begin{array}{l}\text { Universidade } \\
\text { Colégio/Escola } \\
\text { Empresa } \\
\text { Instituto de Pesquisa } \\
\text { Outros }\end{array}$ & $\begin{array}{r}3.260 \\
864 \\
214 \\
703 \\
2.623 \\
\end{array}$ & $\begin{array}{r}833 \\
212 \\
55 \\
163 \\
629\end{array}$ & $\begin{array}{r}814 \\
199 \\
45 \\
163 \\
617\end{array}$ & $\begin{array}{r}532 \\
121 \\
45 \\
102 \\
424\end{array}$ & $\begin{array}{r}477 \\
144 \\
28 \\
80 \\
402\end{array}$ & $\begin{array}{r}257 \\
78 \\
17 \\
81 \\
233\end{array}$ & $\begin{array}{r}189 \\
84 \\
14 \\
77 \\
224\end{array}$ & $\begin{array}{r}158 \\
26 \\
10 \\
37 \\
94\end{array}$ \\
\hline TOTAL & $\begin{array}{l}7.664 \\
100 \%\end{array}$ & $\begin{array}{r}1.892 \\
24,68 \%\end{array}$ & $\begin{array}{r}1.838 \\
23,98 \%\end{array}$ & $\begin{array}{r}1.224 \\
15,97 \%\end{array}$ & $\begin{array}{r}1.131 \\
14,75 \%\end{array}$ & $\begin{array}{r}666 \\
8,68 \%\end{array}$ & $\begin{array}{r}588 \\
7,67 \%\end{array}$ & $\begin{array}{r}325 \\
4,24 \%\end{array}$ \\
\hline
\end{tabular}

Fonte: SBF (2012).

No Brasil, toda a infraestrutura que tem sido montada para o desenvolvimento da nanociência está fundamentada na importação destes bens de capital. Centros de microscopia eletrônica têm sido estruturados em Institutos de Ciência e Tecnologia (ICTs) abrangendo um parque de equipamentos bastante custosos. Ao se adicionar a isto os custos de manutenção, esta soma ainda cresce, tanto do ponto de vista financeiro quanto econômico, influenciada por fatores como o tempo ocioso do equipamento e a dificuldade de acesso a assistência técnica estrangeira.

De acordo com o Gráfico 2, entre os anos de 2000 e 2016, o setor de microscopia eletrônica foi constantemente deficitário, com as importações superando as exportações. Mesmo com a redução das importações a partir de 2013, o déficit da balança comercial referente a estes produtos indica a dependência tecnológica do país em relação aos produtos estrangeiros, de forma que o fornecimento de tais produtos para atender a demanda de produção em nanotecnologia depende basicamente do aumento das importações. 


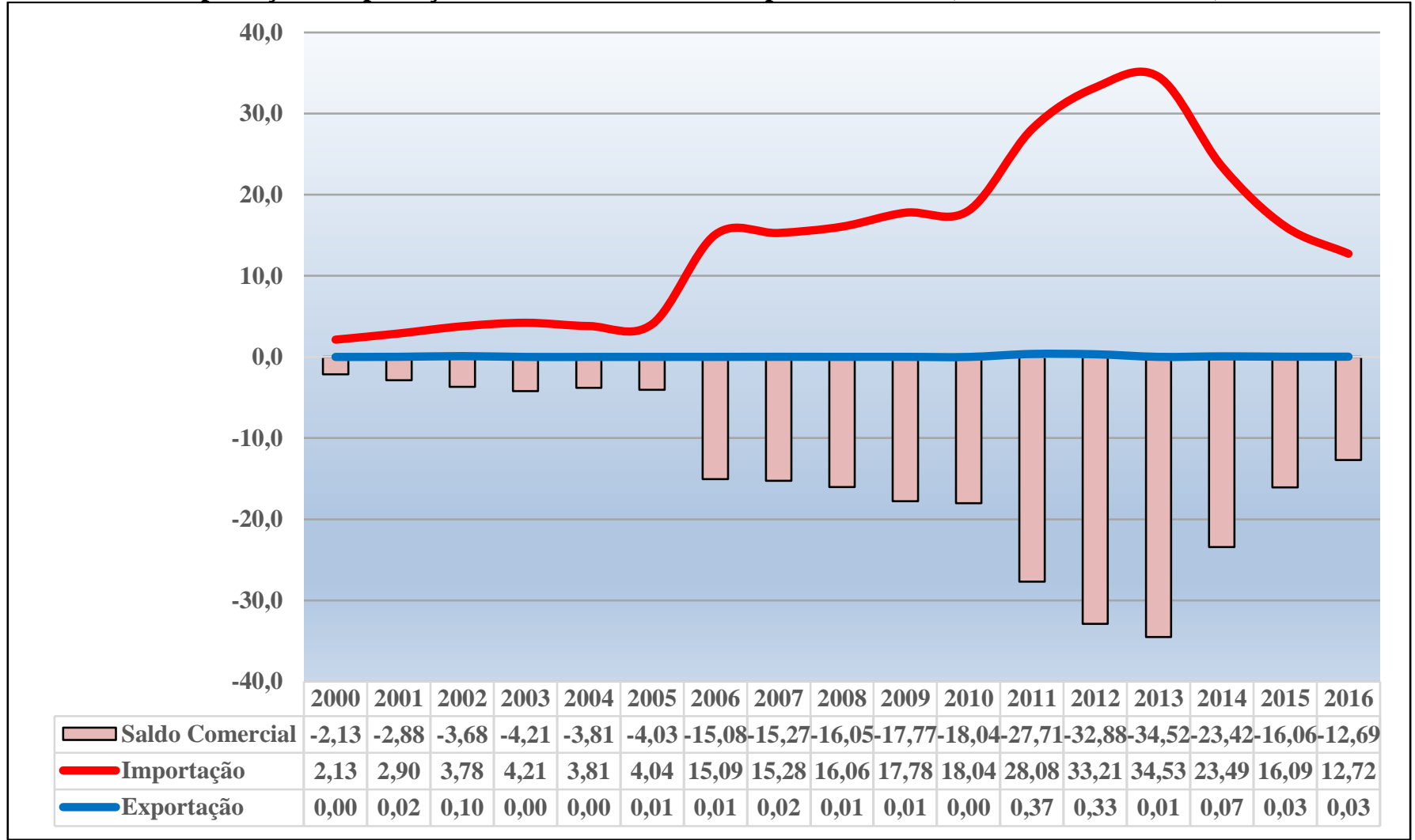

Fonte: SECEX/MDIC. Elaboração própria.

Apesar de alguns avanços no desenvolvimento científico, o Brasil ainda se apresenta em condição desfavorável quando em competição com países mais desenvolvidos, ampliando o espaço para o questionamento dos atuais investimentos em nanociência no Brasil. Piketty (2014) defende que o compromisso do progresso científico está atrelado à geração de bens intangíveis, razão pela qual estes investimentos são historicamente frágeis, sofrendo cortes desestruturantes sempre que a economia nacional passa por processos de contração ${ }^{7}$.

Um dos principais avanços na nanociência está atrelado ao desenvolvimento da Espectroscopia Raman (RAMAN, 1928; RODRIGUES \& GALZERANI, 2012), que é um método poderoso de análise para caracterização química de compostos, vastamente utilizado em campos como a física, a química, a ciência dos materiais e, mais recentemente, nos campos da biologia e da medicina (SCHRADER, 2008). Suas aplicações atuais vão desde a ciência básica, na determinação de propriedades da matéria condensada (CARDONA, 1983), até aplicações em estudos antropológicos de características do solo (JORIO et al., 2012; RIBEIRO-SOARES et al., 2013), protocolos de referência para análise da composição de biodiesel (MIRANDA et al., 2014) e métodos diagnósticos diferenciais para doenças (RYZHIKOVA et al., 2015).

Os avanços da nanociência nos últimos anos provocam uma demanda por desenvolvimentos técnicos e de instrumentação na nanoescala (ZHANG et al., 2012). No caso da espectroscopia Raman, há dois principais limitantes para sua aplicação em escala nanométrica. Um deles é o limite de difração, que restringe a resolução óptica mínima a aproximadamente metade do comprimento de onda da luz incidente,

\footnotetext{
${ }^{6}$ Os dados se referem aos códigos 9012.10.10 (Microscópios eletrônicos) e 9012.90.10 (Partes e acessórios de microscópios eletrônicos), seguindo a Nomenclatura Comum do Mercosul.

${ }^{7}$ Um exemplo específico, mas não limitante, é a pesquisa sobre grafeno, uma folha de átomos de carbono com propriedades eletrônicas, mecânicas e térmicas únicas, importante objeto da ciência de nanoestruturas, que promete modificações drásticas nas áreas tecnológicas, da engenharia à medicina (GEIM e NOVOSELOV, 2007; NOVOSELOV, 2012). A Comunidade Europeia lançou, em 2010, com aporte da ordem de um bilhão de euros, um projeto intitulado "Graphene Flagship", focado no desenvolvimento de tecnologias relacionadas ao grafeno. No Brasil, o estado de Minas Gerais, através da Companhia de Desenvolvimento de Minas Gerais (Codemig), investiu em 2016 cerca de 21,3 milhões de reais no projeto MGgrafeno, uma planta piloto para a produção de grafeno a base de grafite mineral. O estado de São Paulo criou, em 2010, o centro MackGrafe, com um investimento de $\mathrm{R} \$ 26$ milhões para o desenvolvimento de tecnologia a base de grafeno.
} 
que é da ordem de centenas de nanômetros. Outro limitante é a baixa probabilidade de ocorrência do efeito Raman em relação aos outros efeitos da interação luz-matéria. Apesar de específico - e por isso uma poderosa técnica de caracterização - o efeito Raman é pouco provável e de baixa eficiência.

Em 2000 (STÖCKLE et al., 2000) foi relatado o primeiro experimento demonstrando o efeito TERS (sigla em inglês para Tip-Enhanced Raman Spectroscopy, ou espectroscopia Raman auxiliada por sonda), embora o desenvolvimento dos conceitos relacionados a técnica seja bem anterior (NOVOTNY, 2007; YEO et al., 2009). O conceito teórico foi relatado em 1985 (WESSEL, 1985), fundamentado em conceitos de campo próximo, introduzidos pela primeira vez em 1928 (SYNGE, 1928). Nos experimentos conduzidos, os autores incidiram uma fonte de laser monocromática, usualmente utilizada em medidas do efeito Raman e, ao mesmo tempo, aproximaram da amostra uma sonda metálica com ápice de dimensões nanométricas, similar às sondas utilizadas em técnicas já conhecidas de microscopia de varredura por sonda (ou Scanning Probe Microscopy - SPM na sigla em inglês). Os principais efeitos da aproximação da sonda são o aumento do sinal Raman devido à ressonância plasmônica na sonda, e o aumento da resolução espacial por efeitos de campo próximo, que é nesse caso limitada pela dimensão do ápice da ponta metálica. Dessa forma, a nova técnica passou a permitir realizar experimentos de detecção do efeito Raman em nanoestruturas (HARTSCHUH et al., 2003), com eficiência para medir a resposta espectral relacionada a um único átomo (MACIEL et al., 2008).

A técnica TERS, portanto, é uma combinação de duas técnicas anteriormente conhecidas, que permite caracterizar amostras por meio da obtenção de informação química e estrutural, como resultado da realização simultânea da espectroscopia Raman e da microscopia de varredura por sonda. Ao longo dos últimos 15 anos, houve a difusão principalmente acadêmica da técnica TERS, e uma série de conferências internacionais no tema se iniciou no ano de 2009, no National Physical Laboratory (NPL) no Reino Unido.

No âmbito do avanço do conhecimento teórico, pesquisas são direcionadas para a compreensão dos fenômenos de ressonância plasmônica (CANÇADO et al., 2009) e a coerência espacial no regime de campo próximo (BEAMS et al., 2014), ambas fundamentadas em conceitos fundamentais de simetria (JORIO et al., 2017), cujo domínio tem possibilitado aperfeiçoamentos instrumentais, principalmente nas técnicas de fabricação de sondas, o elemento chave da tecnologia.

Da perspectiva de mercado, empresas como NT-MDT, Horiba, Renishaw e RHK já introduziram soluções comerciais, ainda pouco difundidas no mercado mundial, em parte devido à baixa reprodutibilidade e confiabilidade das medições. A falta de reprodutibilidade em medidas em tais equipamentos deve-se, em parte, à precariedade dos processos de reprodutibilidade na produção de sondas de qualidade. A engenharia dos processos de produção de sondas é complexa, e é foco de pesquisas de fronteira. Trata-se de um consumível com alto valor agregado e, por representar o "core" da tecnologia, crucial na obtenção da resolução e do aumento do sinal Raman proporcionado pelo efeito TERS.

Conforme apontou Von Hippel (1998), as fontes de inovação de produtos estão em diferentes ambientes e podem ser desempenhadas por diferentes atores, sejam eles profissionais da indústria de manufatura, fornecedores de componentes, ou mesmo usuários finais. E isto varia conforme o tipo de inovação. Para inovações em instrumentação científica, os maiores inovadores são os usuários, e não os fabricantes. Inovadores, sob esta perspectiva, são definidos como indivíduos ou firmas que primeiramente desenvolvem uma inovação até um estado útil, segundo uma prova documentada, qual seja, a publicação de resultados em revistas científicas, a partir o equipamento melhorado. De acordo com Rosenberg (1982) as novas técnicas de instrumentação, muitas vezes surgidas não intencionalmente, e a difusão de suas aplicações em áreas diversas daquela em que foram originados, são produtos da academia com forte impacto econômico. Tal impacto é muitas vezes subestimado e raramente mensurado.

\subsection{O Laboratório de Nanoespectroscopia}

O Laboratório de Nanoespectroscopia - LabNS da UFMG foi criado em 2006 no Departamento de Física, focado no desenvolvimento das técnicas de espectroscopia Raman e microscopia por varredura de sonda. Contando com financiamento do CNPq, um dos coordenadores do LabNS foi coordenador científico da Rede de Microscopia de Varredura por Sonda - Rede SPM Brasil, no período de 2006 a 2011, com o objetivo de incentivar desenvolvimentos em instrumentação em SPM. Como produto deste projeto, um equipamento para realizar TERS foi construído no LabNS/UFMG. Com este resultado, uma nova rede foi 
financiada pelo CNPq e também coordenada pelo coordenador do LabNS, a Rede Brasileira de Pesquisa e Instrumentação em Nanoespectroscopia Óptica, com duração de 2012 a 2016, projeto com financiamento recentemente renovado. Por meio deste projeto, o LabNS conduziu a replicação do protótipo laboratorial do equipamento para TERS em duas outras instituições de pesquisa do Brasil: o Instituto Nacional de Metrologia, Qualidade e Tecnologia - Inmetro, e a Universidade Federal do Ceará - UFC, instituições pertencentes à rede e com recursos humanos capacitados para conduzir e dar continuidade às pesquisas em TERS. As principais informações sobre o financiamento das atividades do grupo estão na tabela 3.

Tabela 3 - Financiamento das Atividades do LabNS - 2002 a 2017

\begin{tabular}{|c|c|c|c|}
\hline Ano & Recursos & Fonte & Descrição \\
\hline 2002 & $30.350,00$ & $\mathrm{PRPq} / \mathrm{UFMG}$ & Equipamentos/consumo \\
\hline 2003 & $12.432,00$ & \begin{tabular}{|l|l|} 
Fapemig \\
\end{tabular} & Equipamentos/consumo \\
\hline 2004 & $16.000,00$ & $\mathrm{CNPq}$ & Equipamentos/consumo \\
\hline 2005 & $9.109,00$ & Fapemig & Equipamentos/consumo \\
\hline 2006 & $\begin{array}{r}45.000,00 \\
25.000,00 \\
117.066,00 \\
174.814,06 \\
\end{array}$ & $\begin{array}{l}\mathrm{CNPq} \\
\text { Capes/DAAD } \\
\text { Instituto do Milênio } \\
\text { Rede SPM Brasil }\end{array}$ & $\begin{array}{l}\text { Equipamentos/consumo } \\
\text { Custeio } \\
\text { Compra do } 1^{\circ} \mathrm{RHK} \\
\text { Equipamentos/consumo }\end{array}$ \\
\hline 2008 & $246.194,00$ & Rede Nanotubos & Equipamentos/consumo \\
\hline 2009 & $\begin{array}{l}150.000,00 \\
122.000,00 \\
200.000,00 \\
\end{array}$ & \begin{tabular}{|l|} 
AFOSR/USA \\
INCT Nanocarbono \\
CNPq/MCT \\
\end{tabular} & $\begin{array}{l}\text { Equipamentos/consumo } \\
\text { Compra do } 2^{\circ} \mathrm{RHK} \\
\text { Equipamentos/consumo }\end{array}$ \\
\hline 2010 & $\begin{array}{r}144.600,00 \\
6.000,00 \\
\end{array}$ & $\begin{array}{l}\text { Pronex/Fapemig } \\
\text { CNPq/MCT }\end{array}$ & $\begin{array}{l}\text { Equipamentos/consumo } \\
\text { Bolsa de produtividade }\end{array}$ \\
\hline 2011 & $1.347 .854,50$ & $\mathrm{CNPq} / \mathrm{MCT}$ & Equipamentos/consumo e Bolsa de produtividade \\
\hline 2012 & $\begin{array}{l}2.000,00 \\
6.000,00 \\
\end{array}$ & $\begin{array}{l}\text { i-Vision } \\
\text { CNPq/MCT }\end{array}$ & $\begin{array}{l}\text { Equipamentos (doação de câmera para o TERS) } \\
\text { Bolsa de produtividade }\end{array}$ \\
\hline 2013 & $\begin{array}{r}2.167 .000,00 \\
6.000,00 \\
\end{array}$ & \begin{tabular}{|l|} 
Finep \\
CNPq/MCT
\end{tabular} & $\begin{array}{l}\text { Equipamentos/consumo } \\
\text { Bolsa de produtividade }\end{array}$ \\
\hline 2014 & $\begin{array}{l}611.000,00 \\
104.000,00 \\
\end{array}$ & $\begin{array}{l}\mathrm{CNPq} / \mathrm{MCT} \\
\text { CNPq e Capes } \\
\end{array}$ & $\begin{array}{l}\text { Equipamentos/consumo e Bolsa de produtividade } \\
\text { Organização de evento (TERS 4) }\end{array}$ \\
\hline 2015 & $\begin{array}{l}6.000,00 \\
1.000,00 \\
4.932,00 \\
\end{array}$ & $\begin{array}{l}\mathrm{CNPq} / \mathrm{MCT} \\
\text { Governo Suíço } \\
\text { IBM Research Brasil } \\
\end{array}$ & $\begin{array}{l}\text { Bolsa de produtividade } \\
\text { Divulgação Tecnológica } \\
\text { Recursos humanos }\end{array}$ \\
\hline 2016 & $\begin{array}{r}200.000,00 \\
6.000,00 \\
7.700,00 \\
6.125,00 \\
\end{array}$ & $\begin{array}{l}\text { USArmy Research Lab } \\
\text { CNPq/MCT } \\
\text { Governo Suíço } \\
\text { IBM Research Brasil } \\
\end{array}$ & $\begin{array}{l}\text { Equipamentos/consumo } \\
\text { Bolsa de produtividade } \\
\text { Divulgação Tecnológica } \\
\text { Recursos humanos } \\
\end{array}$ \\
\hline 2017 & $6.000,00$ & $\mathrm{CNPq} / \mathrm{MCT}$ & Bolsa de produtividade \\
\hline TOTAL & $5.780 .176,56$ & & \\
\hline
\end{tabular}

Fonte: LabNS. Elaboração própria.

A especialização adquirida pela equipe de pesquisadores do LabNS deve-se, em grande proporção, a avanços conquistados na automatização de processos, na concepção e produção de sondas de alta qualidade, por meio de diferentes métodos de fabricação, bem como à compreensão teórica do efeito TERS. Este fato, aliado à extensa colaboração internacional com grupos de especialistas, construiu autoridade científica e reputação do grupo, refletidos nas publicações científicas e pedidos de patente por seus pesquisadores (CANO-MARQUEZ et al., 2015; VASCONCELOS et al., 2015; PI 1105968-0; PI 11059729; PI 1107185-0; BR 1020120269732; BR 1020120333040; BR1020150103522 e PCT/IB2016/052610; BR1020160291267; PCT/IB2016/057583 e BR1020170079171). Em termos de recursos humanos, o projeto envolveu, até o momento, 11 alunos de iniciação científica, 4 de mestrado, 7 de doutorado, 5 de pós-doutorado e 1 sênior (externo), resultando em 10 patentes nacionais e 5 internacionais.

A partir desses investimentos, o atual estágio de maturidade do grupo contempla o objetivo do eventual empreendimento que seria a comercialização de equipamento completo, contendo todos os componentes necessários à realização de uma medida TERS. E o segmento de clientes foco da comercialização seria o acadêmico (pesquisadores de ICTs), visto que este mercado é bem conhecido do grupo idealizador do projeto. O modelo inicial do empreendimento seria desenhado com o objetivo secundário de profissionalizar a produção do equipamento, sendo isto possível a partir do momento que o protótipo laboratorial evoluísse para um produto comercial, e transpusesse as fronteiras da universidade, por exemplo, por meio da criação de uma spinoff. 


\section{A Matriz de Insumo-Produto}

Esta seção abordará a teoria de insumo-produto, desenvolvida inicialmente por Wassily Leontief, com vistas a servir de base metodológica para o estudo de impacto econômico realizado. Elaborada a partir dos dados do Sistema de Contas Nacionais, a matriz de insumo-produto (MIP) apresenta o fluxo de bens e serviços entre os setores da economia, sendo um quadro de dupla entrada que registra, por um lado, os insumos utilizados pelas diversas atividades econômicas e, por outro, o destino da produção, demonstrando as relações de interdependência entre os setores e permitindo avaliar os impactos de variações na demanda final dos produtos (KURESKI, NUÑEZ e RODRIGUES, 2007).

$\mathrm{O}$ modelo de insumo-produto faz uso dos diversos fluxos entre as distintas atividades econômicas, tendo como base as informações necessárias para descrever as relações entre si e com a demanda final a formação bruta de capital fixo $(I)$, exportações $(X)$, variação de estoques $(V E)$, consumo do governo $(G)$ e consumo pessoal $(C F)$, sua conta de renda e as importações $(M)$. Para Leontief (1964), o ponto central da análise de insumo produto é a ideia segundo a qual há uma relação fundamental entre o volume de produto de uma indústria e a quantidade de insumo que a mesma absorve. Para o modelo são adotadas duas hipóteses, resumidas por Guilhoto (2011): a) homogeneidade, não se considera diferenciação de produtos, havendo razão fixa de insumos (tecnologias fixas no processo produtivo), com rendimento constante de escala (apenas uma tecnologia é empregada na produção de um produto); e b) proporcionalidade, os insumos consumidos em cada atividade são função somente do nível de produção da respectiva atividade. O modelo de Insumo-Produto, representado na Figura 1 , é dividido em setores $(1,2, \ldots, n)$, obtendo para cada um deles a demanda intermediária $\left(\sum x_{i j}\right)$, a demanda final $\left(Y_{n}\right)$ e o valor bruto da produção $\left(X_{n}\right)$. A diferença entre o valor bruto da produção e o consumo intermediário resulta no valor adicionado, que é usado como a remuneração dos fatores de produção como salários, aluguéis, lucros e juros (KURESKI, NUÑEZ e RODRIGUES, 2007).

Figura 1 - Fluxo de bens por setores de origem e destino

\begin{tabular}{|c|c|c|c|c|c|c|}
\hline \multirow{2}{*}{ ATIVIDADES } & \multicolumn{4}{|c|}{ DEMANDA INTERMEDIÁRIA } & \multirow{2}{*}{$\begin{array}{c}\text { Total da } \\
\text { Demanda Final }\end{array}$} & \multirow{2}{*}{$\begin{array}{l}\text { Valor Bruto da } \\
\text { Produção }\end{array}$} \\
\hline & Setor 1 & Setor 2 & $\ldots$ & Setor $n$ & & \\
\hline $\begin{array}{l}\text { Setor } 1 \\
\text { Setor } 2 \\
\quad \vdots \\
\text { Setor } n\end{array}$ & $\begin{array}{c}x_{11} \\
x_{21} \\
\vdots \\
x_{n 1}\end{array}$ & $\begin{array}{c}x_{12} \\
x_{22} \\
\vdots \\
x_{n 2}\end{array}$ & $\begin{array}{c}\cdots \\
\cdots \\
\vdots \\
\cdots\end{array}$ & $\begin{array}{c}x_{1 n} \\
x_{2 n} \\
\vdots \\
x_{n n}\end{array}$ & $\begin{array}{c}Y_{1} \\
Y_{2} \\
\vdots \\
Y_{n}\end{array}$ & $\begin{array}{c}X_{1} \\
X_{2} \\
\vdots \\
X_{n}\end{array}$ \\
\hline Valor Adicionado & $Z_{1}$ & $Z_{2}$ & $\cdots$ & $Z_{n}$ & & \\
\hline Valor Bruto da Produção & $X_{1}$ & $X_{2}$ & $\cdots$ & $X_{n}$ & & \\
\hline
\end{tabular}

Fonte: Kureski, Nuñes e Rodrigues (2007)

Os coeficientes técnicos ${ }^{8}$ são conceituados como as necessidades diretas de insumos dos diversos setores, ou pelas relações intra e interindustriais diretas, calculadas pela seguinte fórmula:

$$
a_{i j}=\frac{x_{i j}}{X_{j}}
$$

Onde:

$$
\begin{aligned}
& \boldsymbol{a}_{\boldsymbol{i j}}=\text { coeficiente técnico; } \\
& \boldsymbol{x}_{\boldsymbol{i} \boldsymbol{j}}=\text { consumo intermediário; } \\
& \boldsymbol{X}_{\boldsymbol{j}}=\text { valor da produção. }
\end{aligned}
$$

Dessa forma, com o aumento da demanda final, ocorrem impactos diretos e indiretos de um aumento unitário da produção da atividade $j$ sobre a produção $i$. Assim, o valor bruto da produção $X_{j}$ é dado por:

$$
\begin{gathered}
X_{1}=x_{11}+x_{12}+\cdots+x_{1 n}+Y_{1} \\
X_{2}=x_{21}+x_{22}+\cdots+x_{2 n}+Y_{2} \\
\vdots \\
X_{n}=x_{n 1}+x_{n 2}+\cdots+x_{n n}+Y_{n}
\end{gathered}
$$

\footnotetext{
${ }^{8}$ Esses coeficientes refletem a estrutura da economia e não apresentam mudanças significativas a curto e médio prazos, o que os tornam importantes indicadores para previsões (LOPES e VASCONCELLOS, 2009).
} 
Isolando-se o valor do insumo da fórmula (1), tem-se:

$$
x_{i j}=a_{i j} X_{j}
$$

Substituindo a equação (3) na equação (2), obtém-se:

$$
\begin{gathered}
X_{1}=a_{11} X_{1}+a_{12} X_{2}+\cdots+a_{1 n} X_{n}+Y_{1} \\
X_{2}=a_{21} X_{1}+a_{22} X_{2}+\cdots+a_{2 n} X_{n}+Y_{2} \\
\vdots \\
X_{n}=a_{n 1} X_{1}+a_{n 2} X_{2}+\cdots+a_{n n} X_{n}+Y_{n}
\end{gathered}
$$

Em forma matricial, a equação (4) pode ser escrita assim:

$$
\boldsymbol{X}=\boldsymbol{A X}+\boldsymbol{Y}
$$

Onde:

$\boldsymbol{X}=$ vetor-coluna do valor bruto da produção;

$\boldsymbol{A}=$ matriz dos coeficientes técnicos;

$\boldsymbol{Y}=$ vetor-coluna do valor da demanda final.

Isolando-se $Y_{i}$ na equação (4), obtém-se:

$$
\begin{gathered}
\left(1-a_{11}\right) X_{1}-a_{12} X_{2}-\cdots-a_{1 n} X_{n}=Y_{1} \\
-a_{21} X_{1}+\left(1-a_{22}\right) X_{2}-\cdots-a_{2 n} X_{n}=Y_{2} \\
\vdots \\
-a_{31} X_{1}-a_{32} X_{2}-\cdots+\left(1-a_{n n}\right) X_{n}=Y_{n}
\end{gathered}
$$

E na forma de matriz, a equação (6) pode ser representada por:

$$
(\boldsymbol{I}-\boldsymbol{A}) \boldsymbol{X}=\boldsymbol{Y}
$$

Em que:

$\boldsymbol{I}=$ matriz identidade;

$\boldsymbol{A}=$ matriz dos coeficientes técnicos;

$\boldsymbol{X}=$ vetor-coluna do valor bruto da produção;

$\boldsymbol{Y}=$ vetor-coluna do valor da demanda final.

Para a determinação dos efeitos diretos e indiretos resultantes do aumento de uma unidade monetária na demanda final $(Y)$, é necessário isolar o valor bruto da produção na equação (7), assim:

$$
\boldsymbol{X}=(\boldsymbol{I}-\boldsymbol{A})^{-1} \boldsymbol{Y}
$$

Onde:

$$
\begin{aligned}
& \boldsymbol{X}=\text { valor bruto da produção; } \\
& (\boldsymbol{I}-\boldsymbol{A})^{-\mathbf{1}}=\text { matriz de Leontief; } \\
& \boldsymbol{Y}=\text { demanda final. }
\end{aligned}
$$

Para avaliar os reais impactos sobre a economia determinados pela matriz insumo-produto é necessário identificar e quantificar os efeitos multiplicadores de impacto setorial de cada atividade econômica. Os dois multiplicadores principais são: (1) multiplicador direto: mede o impacto de um aumento unitário da demanda final de uma determinada atividade sobre uma variável de renda, considerando apenas as atividades que fornecem insumos diretamente a esta atividade; (2) multiplicador total (direto mais indireto): mede o impacto de um aumento unitário da demanda final de uma determinada atividade sobre uma variável de renda, considerando todas as atividades que fornecem insumos, direta e indiretamente a essa atividade. Ao se aplicar um valor de choque pertinente à alteração das demandas, observa-se o impacto causado pelos efeitos multiplicadores dos setores.

Para este trabalho foi utilizada a matriz Insumo-Produto do Brasil de 2013, que é dividida em 68 setores e 128 produtos. A matriz foi construída a partir de dados das Contas Nacionais segundo a metodologia apresentada por Guilhoto e Sesso Filho $(2005,2010)$. No Gráfico 3 são apresentados os multiplicadores de impacto dos setores da matriz. 
Gráfico 3 - Multiplicadores Totais de Impacto dos Setores da MIP

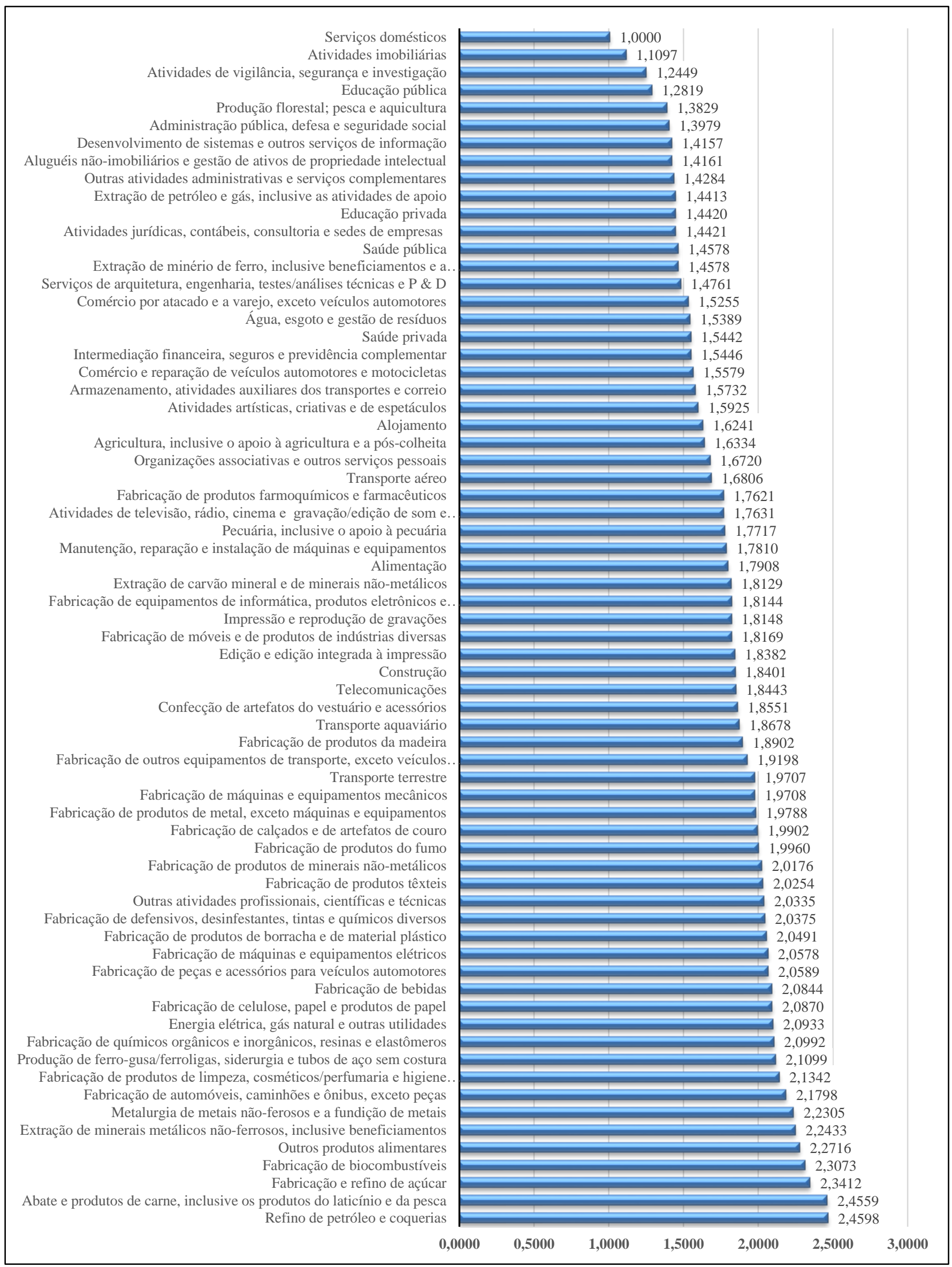

Fonte: MIP 


\section{Estudo do Impacto Econômico e a Nacionalização}

\subsection{A Base de Dados}

A base de dados utilizada para as simulações se refere às informações dos investimentos necessários para a operação da spinoff FabNS no mercado brasileiro pela comercialização de 13 equipamentos TERS durante seus primeiros cinco anos. Para tanto, calculou-se qual seria o gasto ou desembolso total da empresa para este montante de produção, segundo os elementos de despesa do quadro 1, contabilizando também um equipamento permanente da empresa designado para o desenvolvimento. Este cálculo é uma extrapolação do orçamento inicial do modelo de negócios. O modelo parte da produção e entrega sob demanda, onde a receita de uma venda é utilizada para a produção do equipamento seguinte. Para os cálculos da presente análise, já se considera os gastos com a produção e venda do total dos 13 equipamentos no período de cinco anos.

Quadro 1 - Total de desembolsos por elemento de despesa para cinco anos de operação da spinoff

\begin{tabular}{|l|r|}
\hline \multicolumn{1}{|c|}{ Elemento de Despesa } & Desembolso (R\$) \\
\hline Material de consumo em geral & $16.800,00$ \\
\hline Componentes internacionais para a montagem de 13 TERS & $3.593 .060,12$ \\
\hline Impostos (despesas de internação) de componentes importados para a montagem de 13 TERS & $1.827 .347,47$ \\
\hline Componentes nacionais para a montagem de 13 TERS & $1.069 .097,25$ \\
\hline Salários de equipe própria & $869.352,00$ \\
\hline Viagens e Diárias & $288.668,19$ \\
\hline Serviços de terceiros/consultorias/testes & 103.852 .84 \\
\hline Obras e instalações & 32.503 .74 \\
\hline Softwares & $39.036,00$ \\
\hline Máquinas e equipamentos nacionais & \\
Componentes nacionais TERS de desenvolvimento & $82.239,25$ \\
Demais & $69.716,21$ \\
\hline Máquinas e equipamentos importados & \\
Componentes importados TERS de desenvolvimento & $276.389,24$ \\
Demais & $24.071,51$ \\
\hline Despesas operacionais e administrativas & $529.365,08$ \\
\hline TOTAL & $\mathbf{8 . 6 8 5 . 1 4 2 , 3 2}$ \\
\hline
\end{tabular}

Fonte: Elaboração própria.

\subsection{Estimativas de Impacto e Análise de Cenários}

As estimativas de impacto foram realizadas no sentido de avaliar a diferença de impacto na economia entre confeccionar o produto a partir de componentes adquiridos no mercado nacional, ou internacional, ou ambos. Para tanto, desenhou-se três cenários:

Cenário 1: venda do produto a partir de componentes importados

Cenário 2: venda do produto a partir de componentes nacionais e importados

Cenário 3: venda do produto a partir de componentes nacionais

Os Cenários 1 e 2 representam situações factíveis, cuja escolha se daria a partir do direcionamento estratégico da spinoff. O Cenário 1, entretanto, não seria o foco deste estudo, nem tampouco a missão da empresa, uma vez que o argumento proposto neste artigo é a nacionalização na geração de instrumentação científica; sua hipótese é utilizada para comparação. O Cenário 2 é o mais provável e o que reflete a realidade atual do projeto. Já o Cenário 3 é hipotético, uma vez que determinados padrões de qualidade e confiabilidade ainda não podem ser garantidos atualmente pela spinoff a partir somente de componentes nacionais. Entretanto, este último cenário é particularmente relevante para a discussão de que a demanda a partir da operação da empresa poder fomentar o desenvolvimento, no mercado local, de fornecedores especializados.

Por meio da MIP foram calculados os choques nos setores pertinentes, provocados pela alteração das demandas. O Quadro 2 apresenta o detalhamento dos impactos totais nos três cenários em termos de valor bruto da produção ${ }^{9}$.

\footnotetext{
${ }^{9}$ Valor bruto da produção representa toda a receita bruta gerada na economia, ou seja, compreende a totalidade das transferências realizadas mais as vendas efetuadas mais as variações dos estoques.
} 
Quadro 2 - Detalhamento dos impactos totais nos 3 cenários

\begin{tabular}{|c|c|c|c|c|c|c|c|}
\hline \multirow{2}{*}{\multicolumn{2}{|c|}{ Setores }} & \multicolumn{2}{|c|}{ Cenário 1} & \multicolumn{2}{|c|}{ Cenário 2} & \multicolumn{2}{|c|}{ Cenário 3} \\
\hline & & Choque & Impacto & Choque & Impacto & Choque & Impacto \\
\hline 1 & Agricultura, inclusive o apoio à agricultura e a pós-colheita & 0,000 & 0,015 & 0,000 & 0,017 & 0,000 & 0,021 \\
\hline 2 & Pecuária, inclusive o apoio à pecuária & 0,000 & 0,006 & 0,000 & 0,006 & 0,000 & 0,005 \\
\hline 4 & Extração de carvão mineral e de minerais não-metálicos & 0,000 & 0,002 & 0,000 & 0,003 & 0,000 & 0,004 \\
\hline 5 & Extração de petróleo e gás, inclusive as atividades de apoio & 0,000 & 0,020 & 0,000 & 0,043 & 0,000 & 0,070 \\
\hline 6 & Extração de minério de ferro, inclusive beneficiamentos e a aglomeração & 0,000 & 0,001 & 0,000 & 0,003 & 0,000 & 0,005 \\
\hline 7 & Extração de minerais metálicos não-ferrosos, inclusive beneficiamentos & 0,000 & 0,001 & 0,000 & 0,002 & 0,000 & 0,005 \\
\hline 8 & Abate e produtos de carne, inclusive os produtos do laticínio e da pesca & 0,000 & 0,012 & 0,000 & 0,010 & 0,000 & 0,006 \\
\hline 9 & Fabricação e refino de açúcar & 0,000 & 0,003 & 0,000 & 0,004 & 0,000 & 0,005 \\
\hline 10 & Outros produtos alimentares & 0,000 & 0,011 & 0,000 & 0,011 & 0,000 & 0,012 \\
\hline 11 & Fabricação de bebidas & 0,000 & 0,006 & 0,000 & 0,007 & 0,000 & 0,005 \\
\hline 12 & Fabricação de produtos do fumo & 0,000 & 0,000 & 0,000 & 0,000 & 0,000 & 0,000 \\
\hline 13 & Fabricação de produtos têxteis & 0,000 & 0,002 & 0,000 & 0,005 & 0,000 & 0,006 \\
\hline 14 & Confecção de artefatos do vestuário e acessórios & 0,000 & 0,003 & 0,000 & 0,004 & 0,000 & 0,004 \\
\hline 15 & Fabricação de calçados e de artefatos de couro & 0,000 & 0,000 & 0,000 & 0,001 & 0,000 & 0,001 \\
\hline 16 & Fabricação de produtos da madeira & 0,000 & 0,002 & 0,000 & 0,011 & 0,000 & 0,013 \\
\hline 18 & Impressão e reprodução de gravações & 0,000 & 0,011 & 0,000 & 0,059 & 0,000 & 0,079 \\
\hline 19 & Refino de petróleo e coquerias & 0,000 & 0,034 & 0,000 & 0,079 & 0,000 & 0,144 \\
\hline 20 & Fabricação de biocombustíveis & 0,000 & 0,003 & 0,000 & 0,004 & 0,000 & 0,005 \\
\hline 21 & Fabricação de químicos orgânicos e inorgânicos, resinas e elastômeros & 0,000 & 0,008 & 0,000 & 0,026 & 0,000 & 0,061 \\
\hline 22 & Fabricação de defensivos, desinfestantes, tintas e químicos diversos & 0,000 & 0,006 & 0,000 & 0,018 & 0,000 & 0,041 \\
\hline 23 & Fabricação de produtos de limpeza, cosméticos/perfumaria e higiene pessoal & 0,000 & 0,002 & 0,000 & 0,005 & 0,000 & 0,008 \\
\hline 24 & Fabricação de produtos farmoquímicos e farmacêuticos & 0,000 & 0,002 & 0,000 & 0,002 & 0,000 & 0,003 \\
\hline 25 & Fabricação de produtos de borracha e de material plástico & 0,000 & 0,008 & 0,000 & 0,043 & 0,000 & 0,127 \\
\hline 26 & Fabricação de produtos de minerais não-metálicos & 0,000 & 0,011 & 0,000 & 0,012 & 0,000 & 0,011 \\
\hline 27 & Produção de ferro-gusa/ferroligas, siderurgia e tubos de aço sem costura & 0,000 & 0,008 & 0,000 & 0,021 & 0,000 & 0,038 \\
\hline 28 & Metalurgia de metais não-ferosos e a fundição de metais & 0,000 & 0,003 & 0,000 & 0,015 & 0,000 & 0,035 \\
\hline 29 & Fabricação de produtos de metal, exceto máquinas e equipamentos & 0,000 & 0,011 & 0,016 & 0,046 & 0,000 & 0,075 \\
\hline 30 & Fabricação de equipamentos de informática, produtos eletrônicos e ópticos & 0,000 & 0,006 & 1,141 & 1,371 & 5,011 & 5,979 \\
\hline 31 & Fabricação de máquinas e equipamentos elétricos & 0,000 & 0,005 & 0,016 & 0,052 & 0,016 & 0,138 \\
\hline 32 & Fabricação de máquinas e equipamentos mecânicos & 0,000 & 0,004 & 0,000 & 0,011 & 0,000 & 0,024 \\
\hline 33 & Fabricação de automóveis, caminhões e ônibus, exceto peças & 0,000 & 0,001 & 0,000 & 0,001 & 0,000 & 0,004 \\
\hline 34 & Fabricação de peças e acessórios para veículos automotores & 0,000 & 0,006 & 0,000 & 0,008 & 0,000 & 0,015 \\
\hline 37 & Manutenção, reparação e instalação de máquinas e equipamentos & 0,000 & 0,012 & 0,006 & 0,032 & 0,006 & 0,045 \\
\hline 38 & Energia elétrica, gás natural e outras utilidades & 0,000 & 0,050 & 0,063 & 0,152 & 0,063 & 0,164 \\
\hline 39 & Água, esgoto e gestão de resíduos & 0,000 & 0,051 & 0,017 & 0,052 & 0,017 & 0,035 \\
\hline 40 & Construção & 0,000 & 0,080 & 0,000 & 0,057 & 0,000 & 0,028 \\
\hline 41 & Comércio e reparação de veículos automotores e motocicletas & 0,000 & 0,012 & 0,000 & 0,017 & 0,000 & 0,035 \\
\hline 42 & Comércio por atacado e a varejo, exceto veículos automotores & 0,000 & 0,068 & 0,000 & 0,291 & 0,000 & 0,796 \\
\hline 43 & Transporte terrestre & 0,000 & 0,040 & 0,000 & 0,101 & 0,000 & 0,245 \\
\hline 44 & Transporte aquaviário & 0,000 & 0,001 & 0,000 & 0,005 & 0,000 & 0,014 \\
\hline 45 & Transporte aéreo & 0,000 & 0,009 & 0,122 & 0,142 & 0,122 & 0,156 \\
\hline 46 & Armazenamento, atividades auxiliares dos transportes e correio & 0,000 & 0,027 & 0,000 & 0,057 & 0,000 & 0,108 \\
\hline 47 & Alojamento & 0,000 & 0,007 & 0,075 & 0,084 & 0,075 & 0,088 \\
\hline 48 & Alimentação & 0,000 & 0,045 & 0,000 & 0,036 & 0,000 & 0,018 \\
\hline 49 & Edição e edição integrada à impressão & 0,000 & 0,005 & 0,002 & 0,032 & 0,002 & 0,034 \\
\hline 50 & Atividades de televisão, rádio, cinema e gravação/edição de som e imagem & 0,000 & 0,014 & 0,000 & 0,389 & 0,000 & 0,422 \\
\hline 51 & Telecomunicações & 0,000 & 0,039 & 0,017 & 0,096 & 0,017 & 0,134 \\
\hline 52 & Desenvolvimento de sistemas e outros serviços de informação & 0,000 & 0,059 & 0,042 & 0,141 & 0,042 & 0,138 \\
\hline 53 & Intermediação financeira, seguros e previdência complementar & 0,000 & 0,270 & 0,000 & 0,238 & 0,000 & 0,231 \\
\hline 54 & Atividades imobiliárias & 0,000 & 0,021 & 0,084 & 0,131 & 0,084 & 0,155 \\
\hline 55 & Atividades jurídicas, contábeis, consultoria e sedes de empresas & 0,000 & 0,046 & 0,034 & 0,159 & 0,034 & 0,312 \\
\hline 56 & Serviços de arquitetura, engenharia, testes/análises técnicas e P \& D & 0,000 & 0,029 & 0,003 & 0,039 & 0,003 & 0,074 \\
\hline 57 & Outras atividades profissionais, científicas e técnicas & 0,000 & 0,034 & 0,894 & 0,986 & 0,894 & 1,065 \\
\hline 58 & Aluguéis não-imobiliários e gestão de ativos de propriedade intelectual & 0,000 & 0,017 & 0,010 & 0,046 & 0,010 & 0,065 \\
\hline 59 & Outras atividades administrativas e serviços complementares & 0,000 & 0,126 & 0,000 & 0,131 & 0,000 & 0,143 \\
\hline 60 & Atividades de vigilância, segurança e investigação & 0,000 & 0,037 & 0,000 & 0,034 & 0,000 & 0,031 \\
\hline 61 & Administração pública, defesa e seguridade social & 3,412 & 3,422 & 1,827 & 1,848 & 0,000 & 0,035 \\
\hline 62 & Educação pública & 0,000 & 0,001 & 0,000 & 0,001 & 0,000 & 0,003 \\
\hline 63 & Educação privada & 0,000 & 0,006 & 0,000 & 0,012 & 0,000 & 0,014 \\
\hline 64 & Saúde pública & 0,000 & 0,000 & 0,000 & 0,000 & 0,000 & 0,000 \\
\hline 65 & Saúde privada & 0,000 & 0,001 & 0,000 & 0,001 & 0,000 & 0,000 \\
\hline 66 & Atividades artísticas, criativas e de espetáculos & 0,000 & 0,004 & 0,000 & 0,019 & 0,000 & 0,022 \\
\hline 67 & Organizações associativas e outros serviços pessoais & 0,000 & 0,007 & 0,000 & 0,020 & 0,000 & 0,041 \\
\hline 68 & Serviços domésticos & 0,000 & 0,000 & 0,000 & 0,000 & 0,000 & 0,000 \\
\hline & TOTAL & 3,412 & 4,770 & 4,424 & 7,357 & 6,450 & 11,792 \\
\hline
\end{tabular}

Fonte: Elaboração própria a partir da MIP.

A Tabela 4 mostra o resumo dos resultados obtidos e contém a descrição dos cenários, do choque aplicado, do impacto gerado e do multiplicador geral resultado da matriz. 
Tabela 4 - Resultados da aplicação da MIP na estimativa de impacto econômico da spinoff

\begin{tabular}{|c|c|c|c|c|}
\hline \multirow{2}{*}{ Cenários } & \multirow{2}{*}{ Descrição } & \multicolumn{3}{|c|}{ Produção (R\$) } \\
\hline & & Choque & Impacto & Multiplicador Geral \\
\hline Cenário 1 & $\begin{array}{l}\text { Todos os equipamentos são importados, a um preço } \\
\text { unitário médio de } \mathrm{R} \$ 1.749 .719,16 \text {, sendo o choque na } \\
\text { economia causado apenas pela arrecadação de } \\
\text { impostos (aquisição pela universidade com alíquota de } \\
15 \% \text { do imposto de importação). }\end{array}$ & $3.411 .952,36$ & $4.769 .548,56$ & 1,398 \\
\hline Cenário 2 & $\begin{array}{l}\text { A FabNS está em operação produzindo os TERS, } \\
\text { importando apenas parte dos componentes dos } \\
\text { equipamentos. }\end{array}$ & $4.407 .508,24$ & 7.357.160,58 & 1,669 \\
\hline Cenário 3 & $\begin{array}{l}\text { A FabNS está em operação e a importação dos } \\
\text { componentes é substituída pela produção nacional, ou } \\
\text { seja, substituição de importação via desenvolvimento } \\
\text { de capacidade tecnológica nacional. }\end{array}$ & $6.449 .610,13$ & $11.791 .593,35$ & 1,828 \\
\hline
\end{tabular}

Fonte: Elaboração própria a partir da MIP.

No Cenário 1, o choque de $\mathrm{R} \$ 3,4$ milhões está relacionado ao pagamento de impostos com a importação dos equipamentos, sendo o choque aplicado ao setor "Administração pública, defesa e seguridade social". O impacto gerado seria de R\$ 4,7 milhões na economia, o que representa um fator multiplicador de 1,398. Apesar da importação de todos os componentes, este cenário movimentaria, ainda que pouco, a economia. No Cenário 2, o choque é aplicado em 17 setores da economia, com valor de R\$ 4,4 milhões, o que causaria um impacto de $\mathrm{R} \$ 7,3$ milhões. O fator multiplicador geral neste caso é de 1,668. No Cenário 3, onde todos os componentes seriam adquiridos nacionalmente para a montagem, produção e venda do equipamento, o choque é de $\mathrm{R} \$ 6,4$ milhões em 16 setores da economia. Neste caso, exclui-se o setor impactado pelos impostos de importação ("Administração pública, defesa e seguridade social”), em relação ao Cenário 2. O choque para o Cenário 3 causa um impacto de $\mathrm{R}$ \$11,8 milhões na economia, com fator multiplicador geral de 1,828 .

Destaca-se que nesta análise preliminar, para todos os cenários, consideraram-se apenas os investimentos ou desembolsos a serem realizados para a produção dos equipamentos e não as receitas advindas da atividade. Portanto, as projeções mostradas podem ser consideradas como um limite inferior dos impactos totais ${ }^{10}$. Os setores impactados em cada um dos cenários podem ser observados no quadro 2. Cabe ressaltar que o crescimento dos diversos setores, apesar da ausência de investimento direto, demonstra a interdependência entre os setores como preconizado por Leontief.

\section{Considerações Finais}

O cenário do desenvolvimento científico brasileiro, no qual a pesquisa acadêmica foi instalada tardiamente e com base produtiva dominada, em setores-chave, por multinacionais, levou a um quadro de baixa inovação para o tamanho da economia brasileira. A compra de equipamentos científicos de alta tecnologia para a pesquisa acadêmica no Brasil é realizada, na maioria das vezes, por meio de financiamento de órgãos de fomento através de aquisição internacional. A participação do Estado no apoio à inovação não é apenas desejável, é condição sine qua non para o desenvolvimento rumo à sociedade do conhecimento.

No caso analisado neste artigo, demonstrou-se que a criação de uma spinoff para a venda de 13 equipamentos para TERS, para o segmento de clientes do mercado acadêmico, causaria um impacto de aproximadamente $\mathrm{R} \$ 7,3$ milhões (Cenário 2), mesmo com parte dos componentes importados. Em comparação à importação total do equipamento, o Cenário 2 é mais favorável que o Cenário 1 , ou seja, produzir os equipamentos no país movimenta mais a economia que importá-los, mesmo que o valor dos impostos seja elevado.

Os resultados obtidos com a análise da aplicação da MIP ao estudo de caso da criação de spinoff para a venda de equipamentos TERS indicam que o investimento em empresas de base tecnológica de instrumentação a partir do conhecimento gerado na universidade é de relevante impacto econômico e deveria ser foco de políticas públicas específicas no país. O argumento se fortalece quando se considera os

\footnotetext{
${ }^{10}$ As projeções de um modelo de insumo-produto já são sobrevalorizadas em razão dos preços serem rígidos e, portanto, não captar efeitos de substituição entre os insumos. Como se trata de um modelo de equações lineares em um ambiente econômico com hipóteses de retornos constantes de escala e oferta ilimitada de insumos, os cenários elaborados apresentam resultados proporcionais e similares em termos de estrutura, apenas com modificações nos valores das variações projetadas.
} 
outros transbordamentos possíveis com a produção nacional: formação de recursos humanos especializados, fomento à criação de fornecedores de componentes de alto valor agregado, fluxo de conhecimento entre os atores da cadeia de valor e soberania científica e industrial.

Ao integrar atores (academia, governo, indústria) e grandes áreas do conhecimento (ciência, engenharia, metrologia, economia), o campo da instrumentação pode assumir um protagonismo na agenda da inovação tecnológica de um país, como é o caso da Alemanha e dos Estados Unidos. Sob a perspectiva socioeconômica, deter o conhecimento de tecnologias de instrumentação é sinônimo de soberania e competitividade científica e industrial para um país. Neste trabalho, além de apontar a relevância do tema, demonstrou-se que o investimento governamental em estruturas para gerar instrumentação de alta tecnologia pode ser superavitário. Em adição à perspectiva econômica, os transbordamentos do investimento chegariam também à formação de recursos humanos, construção de uma indústria forte de fornecedores especializados, fluxo de informação, conhecimento e aprendizado entre setores diretamente envolvidos, para citar alguns. Apesar de não ser medido diretamente, esses elementos reforçam uma função importante da universidade, pois é dela o papel essencial, e praticamente exclusivo, de treinamento de mãode-obra qualificada, principalmente de cientistas e engenheiros que serão absorvidos pelas firmas. $\mathrm{O}$ desempenho da spinoff, dentro do sentido de eficiência schumpeteriana, passa a ser explicado, em primeiro lugar, pelos recursos que possui e, em segundo, pelo conhecimento e capacitações que foram acumulados e que estão incorporados em seus ativos e em suas rotinas, principalmente as dinâmicas.

A ideia do negócio na universidade se beneficia por terem acesso a novos conhecimentos e ao avanço científico, talvez abrindo novas oportunidades a serem exploradas, principalmente por meio de uma atividade de pesquisa continuada. Em segundo, por ter acesso aos laboratórios e equipamentos das universidades, além de acesso a recursos humanos altamente qualificados, inclusive para identificação de alunos para recrutamento futuro. As universidades, por outro lado, adquirem maior competência ao conhecer os problemas reais, conhecendo a realidade empresarial e os problemas existentes e, assim, obtendo novas informações para suas atividades de ensino, incorporando novas informações nos processos de ensino e pesquisa, principalmente para a pós-graduação. Além disso, a interação com empresas abre a possibilidade para geração de rendas adicionais para os pesquisadores universitários e para os centros de pesquisa, permitindo, inclusive, a expansão das expectativas profissionais dos pesquisadores individuais.

Esse estudo mostra que, com a nacionalização da produção de bens de consumo ou capital, é possível amenizar o processo de dependência tecnológica. Através da estruturação de um setor industrial voltado para a produção de bens de capital e consumo, e políticas públicas voltadas ao estímulo à criação de empresas nacionais de alta tecnologia, o investimento em ciência torna-se superavitário, independentemente dos resultados científicos, tecnológicos ou de inovação advindos da pesquisa relacionada. Defende-se, ainda, que esta é uma transformação necessária no ambiente de inovação brasileiro, caso queira-se adotar o conhecimento como base para o desenvolvimento científico e tecnológico. Em nanociência e nanotecnologia, esta transformação faz-se especialmente necessária, por ser um campo tecnológico que está em sua infância.

\section{Referências}

ALVES, Oswaldo Luiz. Nanotecnologia e desenvolvimento. Campinas, SP: LQES NEWS, 2005.

ARROW, K. J. Economic welfare and the allocation of resources for invention. In: NELSON, R. The rate and direction of inventive activity. NBER: Princeton University Press, 1962, p. 609-629.

ASSAD, A. L. D. Integração Universidade-Empresa: buscas e desafios em época de globalização. In: Instituto Brasileiro Informação em C\&T. (Org.). Interação Universidade-Empresa. Brasília: IBICT, 1998.

BEAMS, R.; CANÇADO, L.G.; OH, S-H.; JORIO, A., NOVOTNY, L. Spatial coherence in near-field Raman scattering. Physical Review Letters, 113, 186101 (2014).

BERNAL, J.D. The Social Function of Science. London: Routledge \& Kegan Paul, 1939.

CANÇADO, L.G.; JORIO, A.; ISMACH, A.; JOSELEVICH, E.; HARTSCHUH, A.; NOVOTNY, L. Mechanism of near-field Raman enhancement in one-dimensional systems. Physical Review Letters 103, 186101 (2009). 
CANO-MARQUEZ, A. G.; SCHMIDT, W.G.; RIBEIRO-SOARES, J.; CANÇADO, L.G.; RODRIGUES, W.N.; SANTOS, A.P.; FURTADO, C.A.; AUTRETO, P.A.S.; PAUPITZ, R.; GALVÃO, D.S.; JORIO, A. Enhanced Mechanical Stability of Gold Nanotips through Carbon Nanocone Encapsulation. Sci. Rep. 5, 10408; doi: 10.1038/srep10408 (2015).

CARDONA, M. Ed. Light Scattering in Solids. Springer Topics in Applied Physics. First Ed. 1983.

CASSIOLATO, J. e ALBUQUERQUE, E. M. Cooperação empresa-universidade: uma revisão geral. In: Instituto Brasileiro Informação em C\&T. (Org.). Interação Universidade-Empresa. Brasília: IBICT, 1998.

DAGNINO, R. A relação universidade-empresa no Brasil e o 'argumento da Hélice Tripla'. Convergência, v. 11, n. 35, 2004.

FEIJÓ, Carmem Aparecida; RAMOS, Roberto Luis Olinto (Org.). Contabilidade Social: a nova referência das contas nacionais do Brasil. 3 ed. rev. Rio de janeiro: Elsevier Campus, 2007, 326 p.

FERRARI, M. A. R. A Economia Evolucionária Neo-schumpeteriana e o Novo Institucionalismo: Em Busca de Explicações para a Mudança Tecnológica e Institucional. Encontro Nacional da Sociedade Brasileira de Economia Política. Vitória, 2006.

FERREIRA, Paulo J.; ALBUQUERQUE, José Maria. A nova economia: nanotecnologia. Jornal Público, v. 20, 2005.

FRANÇA, T. C. V. Redes de Difusão Universidade-Empresa: um estudo exploratório para a UFSC. Dissertação de Mestrado. Programa de Pós-Graduação em Engenharia de Produção, UFSC, 2001.

FREEMAN, C.; SOETE, L. A Economia da Inovação Industrial. Campinas, SP: Editora da Unicamp. 2005. GEIM, Andre K.; NOVOSELOV, Konstantin S. The rise of graphene. Nature materials, v. 6, n. 3, p. 183 191, 2007.

GUILHOTO, J. J. M. (2011). Análise de Insumo-Produto: Teoria, Fundamentos e Aplicações. Livro em Elaboração. Departamento de Economia. FEA-USP. Disponível em <http:IImpra.ub.unimuechen.de/32566/2/MPRA_paper_32566.pdf>. Acesso em: 01 de mar. 2012.

GUILHOTO, J.J.M., U.A. SESSO FILHO. "Estimação da Matriz Insumo-Produto a Partir de Dados Preliminares das Contas Nacionais”. Economia Aplicada. Vol. 9. N. 2. pp. 277-299. Abril-Junho, 2005.

"Estimação da Matriz Insumo-Produto Utilizando Dados Preliminares das Contas Nacionais: Aplicação e Análise de Indicadores Econômicos para o Brasil em 2005". Economia \& Tecnologia. UFPR/TECPAR. Ano 6, Vol 23, Out, 2010.

HARTSCHUH, A. et al. "High-resolution near-field Raman microscopy of single-walled carbon nanotubes." Physical Review Letters 90.9 (2003): 095503.

JORIO, A. et al. Microscopy and spectroscopy analysis of carbon nanostructures in highly fertile Amazonian anthrosoils. Soil and Tillage Research, v. 122, p. 61-66, 2012.

JORIO, A et al. Symmetry-derived selection rules for plasmon-enhanced Raman scattering. Physical Review B 2017. Submetido.

KURESKI, R.; NUÑEZ, B. C; RODRIGUES, R. L. Multiplicadores de emprego e renda da indústria brasileira de celulose, papel e gráfica em 2003: uma aplicação da matriz de insumo-produto In: Anais do Congresso Brasileiro de Economia e Sociologia Rural, 45, 2007, Londrina - PR: SOBER, 2007, 19 p.

MACIEL, Indhira O. et al. Electron and phonon renormalization near charged defects in carbon nanotubes. Nature materials, v. 7, n. 11, p. 878-883, 2008.

MAIA, M. das G. S. F. A Integração Universidade/Empresa como Fator de Desenvolvimento Regional: Um Estudo da Região Metropolitana de Salvador. Tese de Doutorado. Barcelona: UB, 2005. 
MCTI. Ministério da Ciência, Tecnologia e Inovação. Indicadores de Ciência e Tecnologia. Brasília, DF, 2017.

MIRANDA, A.M.; CASTILHO-ALMEIDA, E.W.; FERREIRA, E.H.M.; MOREIRA, G.F.; ACHETE, C.A.; ARMOND, R.A.S.Z.; DOS SANTOS, H.F.; JORIO, A. Line shape analysis of the Raman spectra from purê and mixed biofuels esters compounds. Fuel 115 (2014) 118-125.

MORANDI, A. M. et al. Convergência de Renda e dinâmica regional no Espírito Santo. In: ENCONTRO DE ECONOMIA DO ESPÍRITO SANTO, 3, 2012, Vitória. Anais eletrônicos... Disponível em: <http: Ilwww.encontroeconoiaes.com/index.html>. Acesso em: 10 fev. 2017.

NELSON, R. The simple economics of basic scientific research (1959). In: MIROWSKI, P.; SENT, E-M. (Ed.). Science bought and sold: essays in the economics of science. Chicago: University of Chicago, 2002.

NOVOSELOV, Konstantin S. et al. A roadmap for graphene. Nature, v. 490, n. 7419, p. 192-200, 2012.

NOVOTNY, Lukas. The history of near-field optics. Progress in optics, v. 50, p. 137, 2007.

PAGANO, M.C.; RIBEIRO-SOARES, J.; CANÇADO, L.G.; FALCÃO, N.P.S.; GONÇALVES, V.N.; ROSA, L.H.; TAKAHASHI, J.A.; ACHETE, C.A.; JORIO, A. Depth dependence of black carbono structure, elemental and microbiological composition in anthropic Amazonian dark soil. Soil \& Tillage Research, v. 155, p. 298-307, 2016.

PIKETTY, T. Capital in the twenty-first century. 2014.

RAMAN, C. V. "A new radiation". Indian J. Phys. 2: 387-398. 1928.

RAPINI, M. S. Interação universidade-indústria no Brasil: uma análise exploratória a partir do diretório dos grupos de pesquisa do CNPq. Dissertação de Mestrado. Rio de Janeiro: UFRJ/IE, 2004.

RAPPEL, E. Integração universidade-indústria: os "porquês" e os "comos". In: Instituto Brasileiro Informação em C\&T. (Org.). Interação Universidade-Empresa. Brasília: IBICT, 1999.

RIBEIRO-SOARES, J. et al. The use of Raman spectroscopy to characterize the carbon materials found in Amazonian anthrosoils. Journal of Raman Spectroscopy, v. 44, n. 2, p. 283-289, 2013.

RODRIGUES, Ariano De Giovanni; GALZERANI, José Cláudio. Espectroscopias de infravermelho, Raman e de fotoluminescência: potencialidades e complementaridades. Revista Brasileira de Ensino de Física, v. 34, n. 4, p. 4309-1, 2012.

ROSENBERG, N. Quão exógena é a ciência? In: Por dentro da caixa-preta: tecnologia e economia. Tradutor: José Emílio Maiorino - Campinas, SP: Editora Unicamp, 2006, 215-241.

ROSENBERG, N. Scientific instrumentation and university research. In: Exploring the Black Box: Technology, economics and history. Cambridge, U.K.: Cambridge University Press, 1982, 250-263.

RYZHIKOVA, E.; KAZAKOV, O.; HALAMAKOVA, L.; CELMINS, D.; MALONE, P.; MOLHO, E.; ZIMMERMAN, E.A.; LEDNEV, I.K. Raman spectroscopy of blood serum for Alzheimer's disease diagnostics: specificity relative to other types of dementia. J Biophotonics. 2015 July; 8(7): 584-596.

SCHRADER, B. (Ed.). Infrared and Raman spectroscopy: methods and applications. John Wiley \& Sons, 2008.

SESSA, C. B. Uma abordagem integrada da Economia Evolucionista e da Nova Economia Institucional para entendimento da relação universidade-empresa: 0 caso NEXEM/UFES. Dissertação de Mestrado. Vitória: UFES/ME, 2009.

SHINN, T. Scientific instrumentation, history and sociology of. International Encyclopedia of the Social \& Behavioral Sciences, 2001, pp. 13737-13741.

SBF. Sociedade Brasileira de Física. A Física e o desenvolvimento nacional. Centro de Gestão e Estudos Estratégicos (CGEE). Brasília, DF, 2012. 
STAL. E.; CERANTOLA, W.A. PADCT: uma avaliação preliminar do subprograma de instrumentação. Revista de Administração, v.24, n.2, p. 83-93, abril-junho, 1989.

STÖCKLE, R.M.; SUH, Y.D.; DECKERT, V.; ZENOBI, R. Nanoscale chemical analysis by tip-enhanced Raman Spectroscopy. Chem. Phys. Lett. 318 (2000): 131-36.

SYNGE, E. H. "A suggested model for extending microscopic resolution into the ultra-microscopic region," Phil. Mag., vol. 6, pp. 356-362, 1928.

VASCONCELOS, T.L.; ARCHANJO, B.S.; FRAGNEAUD, B.; OLIVEIRA, B.S.; RIIKONEN, J.; LI, C.; RIBEIRO, D.S.; RABELO, C.; RODRIGUES, W.N.; JORIO, A.; ACHETE, C.A.; CANÇADO, L.G. Tuning Localized Surface Plasmon Resonance in Scanning Near-Field Optical Microscopy Probes. ACS Nano 9, 6297 (2015)

VOGT, C. e CIACCO, C. O papel do Instituto Unimep nas relações universidade e empresa. In: Instituto Brasileiro Informação em C\&T. (Org.). Interação Universidade-Empresa. Brasília: IBICT, 1998.

VON HIPPEL, E. The Sources of Innovation. Oxford University Press, Oxford, UK (1988).

WESSEL, J., “Surface-enhanced optical microscopy,” J. Opt. Soc. Am. B, vol. 2, pp. 1538-1540, 1985.

WOLFFENBUTTEL, A. P. Incubadoras universitárias de empresas: um estudo de caso na incubadora de empresas de base tecnológica da UNISINOS. Dissertação de Mestrado em Administração. Porto Alegre: UFRGS, 2001.

YEO, B-S.; STADLER, J.; SCHMID, T.; ZENOBI, R.; ZHANG, W. Tip-enhanced Raman spectroscopy its status, challenges and future directions. Chemical Physics Letters 472 (2009) 1-13.

ZHANG, M.Q.; WANG, R.; WU, X.B., WANG, J. Principle, systems, and applications of tip-enhanced Raman spectroscopy. Sci. China Phys. Mech. Astron. August 2012 Vol.55 No8: 1335-1344. 